\title{
Why resource regimes fail in the long run? The role of Institutional Complexity Traps and Transversal Transaction Costs*
}

\author{
Thomas Bolognesi $^{\dagger} \quad$ Stephane Nahrath ${ }^{\ddagger} \quad$ Florence Metz ${ }^{\S}$
}

June 13, 2018

\begin{abstract}
Environmental governance faces inconsistencies limiting its efficiency and ability to frame a sustainable co-evolution of Human and Nature. Regarding natural resource governance in developing countries, frictions in between policy design and property rights allocation cause these inconsistencies. It is consensual that there are institutional complexity and lack of integration within these governance systems. Nevertheless, very few studies provide a framework explaining how environmental governance do evolve to lead to this output. We argue that governance is subject to transversal transaction costs over the long term. They are at the origin of inconsistencies between policy design and property rights allocation which create an institutional complexity trap. We define institutional complexity traps and identify their pathways by focusing on water governance evolution in Belgium, France, Italy, Netherlands, Spain and Switzerland from its beginning to present days. Then, we highlight the role of transversal transaction costs as a factor of institutional complexity traps.
\end{abstract}

Keywords: Environmental governance, Policy design, Political-economy, Transaction costs, Long-term perspective

JEL Codes: Q58, P48, E61, N5

\footnotetext{
${ }^{*}$ We are grateful to Jorg Balsiger, Kevin Blake, Christian Bréthaut, Elodie Charrière, Joe Collins, Franklin ObengOdoom, and seminar audiences in Geneva for discussions and comments that greatly improved the manuscript. Any errors remain our own.

${ }^{\dagger}$ University of Geneva, thomas.bolognesi@unige.ch

${ }^{\ddagger}$ University of Lausanne and University of Technology Sydney, stephane.nahrath@unil.ch

${ }^{\S}$ ETH Zurich, florence.metz@usys.ethz.ch
} 


\section{Introduction}

Institutions strongly determine human behaviour and our impact on the environment. In that respect, governance design is central to the study of sustainability and sustainable use of natural resources, especially regarding frictions and failures (Ostrom, 1990, 2005; Vatn, 2005). Recently, studies have moved from a static perspective to a dynamic understanding of the relationship between institutions and sustainability (Fuenfschilling and Truffer, 2014; van den Bergh et al., 2011; Young, 2010). Nonetheless, these two perspectives are somehow conflicting and limit our understanding of institutional evolution, institutional design and sustainability. This paper proposes to fill this gap by providing an understanding of the institutional dynamics that explain frictions in institutional design.

The literature on the statics of institutions points out institutional frictions as a key trigger of unsustainable outcomes. Empirical evidence has put into light different reasons for these frictions within governance structure. In extreme cases, rules might be contradictory. However, more often authors observe overlaps and interplay that reduce incentives for strength, clarity and feasibility of planning or rooms for manoeuvre (Bakker, 2010; Bolognesi, 2014; Correljé et al., 2007; Moss, 2004; Saleth and Dinar, 2008). Moreover, behaviour of actors facing governance design, mainly during the implementation of public policies, is under scrutiny. Studies emphasise that actors may game the rules or cheat (Kaika and Page, 2003; Laffont and Martimort, 2009), fail to comply or be subjected to significant transaction costs which alter the efficiency of coordination (McCann et al., 2005; Mettepenningen et al., 2009; Phan et al., 2017).

Theory offers three principal explanatory mechanisms for frictions in coordination and governance. In that respect, implementation has been conceptualized as a complex process wherein the quality of organizational, administrative and institutional inter-linkages are key drivers of success (Bromley, 1991; Ostrom, 2011; Pahl-Wostl et al., 2010; Saleth and Dinar, 2005; Teisman and Edelenbos, 2011). A second mechanism is the impact of transaction costs which produce uncertainty and difficulties in implementing environmental policies (Challen, 2000; Coggan et al., 2010; Garrick et al., 2013; Krutilla and Krause, 2010; Marshall, 2013). The third mechanism is the role of informal institutions and internal values as sources of pro-environmental behaviour (Bamberg and Möser, 2007) or conflicts with formal institutions (Ostrom, 2009).

The literature on institutional dynamics does not provide any convergent perspectives. Instead of focusing on friction, it emphasises a certain functionalism in institutional dynamics that do not lead to positive outcomes. Two main streams structure this field. The first is evolutionary institutionalism which assumes that institutions evolve following a Darwinist process (Hodgson and Knudsen, 2010). Competition among institutions operates through a selection process which maintains the most efficient or legitimate ones. The second stream emphasises a trial-error process (North, 2005). Actors refine institutions across time to enhance their efficiency or to make them more appropriate 
with local contingencies (Cleaver, 2002; Ostrom, 2005). Nonetheless, this functionalist perspective is not as naive; it is framed by power relations and path dependency (Brousseau et al., 2011) ${ }^{1}$.

A discrepancy appears between the static and the dynamic perspective of institutions. In this paper, we aim to reconcile these views by providing dynamic explanations of static outcomes and why resource regimes fail in the long run. Consequently, we have chosen to investigate mechanisms in institutional dynamics that produce frictions in natural resource governance. We argue that institutional dynamics lead to an Institutional Complexity Trap (ICT) because of increasing Transversal Transaction Costs (TTC). These two new concepts are interlinked as ICT is used to reflect institutional dynamics at the macro level in the long run and TTC appears at the micro level over the short term. Therefore, we propose two main contributions. First, we demonstrate that the existence of an ICT contributes to absorbing the discrepancy between static and dynamic perspectives on environmental governance. Second, by offering the TTC concept we contribute to the literature on environmental policy and transaction costs, and to explain the pattern leading to an ICT.

Five sections structure the paper. Section 2 elaborates on the theoretical foundations of ICT. Section 3 presents our research design. Section 4 discusses results confirming the existence of an ICT. Section 5 discusses TTC and their role in the dynamics leading to an ICT. Section 6 concludes.

\section{Institutional Complexity Trap: a formal model}

\subsection{Resource regime dynamics and Institutional Complexity Trap}

The "Institutional Resource Regime" (IRR) framework, which has been previously presented in an article published in Ecological Economics (Gerber et al., 2009), can certainly help formulate a first description of the "Institutional Complexity Trap" (ICT) phenomenon. As suggested in this previous article, the characteristics of an IRR may vary according to two main dimensions: its extent and its coherence. ${ }^{2}$.

The extent refers to the total number of uses (goods and services, G \& S) which are regulated by an IRR at a given time: the more $\mathrm{G} \& \mathrm{~S}$ regulated, the larger the extent (i.e. scope) of the

\footnotetext{
${ }^{1}$ Besides the understanding of reality, methodological aspects contribute to explain the preponderance of functionalist perspectives. Knight (1992) noted that because institutional dynamics are highly complex, we should address complexity gradually. He then argues that theory should go through naive, functionalist and sophisticated stages.

2 "The concept of the Institutional Resource Regime (IRR), which refers to the ownership and rights to a resource and to the policies regulating the use and protection of the resource, enables the integration of policy analysis and institutional economics and considers all of the aforementioned dimensions - i.e. resources, actors and institutional rules - in one and the same analytical framework. The central postulate of the IRR approach assumes that the two steering dimensions are complementary and that both must be considered simultaneously to facilitate the understanding of the actual uses made of the goods and services provided by a resource." (Gerber et al., 2009, 802)
} 
regime. In this regard, the extension of an IRR refers to the process of increasing the extent of an IRR, i.e. the number of $\mathrm{G} \& \mathrm{~S}$ regulated by the regime.

Coherence refers to the way in which the various sets of rules are more or less conflicting. Coherence (or incoherence) is thus a way of assessing and characterising the linkages between IRR's four regulation modes which contribute to allocate the bundle of rights associated to a given resource (Schlager and Ostrom, 1992). Mode 1 and 2 are public policy regulatory measures with respectively no impact (informational and incentive instruments like information campaigns, subsidies or taxes) and impacts on the content of the property rights regimes (regulatory instruments like obligations, restrictions, limitations or quotas). Regulation modes 3 and 4 set up property rights structure by respectively re-defining the content of property rights as an institution (e.g. introduction of State guarantee of private property in the Constitution, legal recognition of material expropriation or introduction of condominium property in the Civil code) or changing property rights' allocation (e.g. privatization or nationalization). Thus, one of the most challenging issues for policy makers consists in creating or maintaining coherence between public law regulations (modes 1 and/or 2) and private law regulations (modes 3 and/or 4$)^{3}$.

The combination of both coherence and extent characterises the level of integration of a regime. The (increasing) level of integration being the following (increasing) level of integration being the following (Table 1) : No-Regime, Simple, Complex, Integrated. The IRR framework is thus founded on two postulates: (1) the higher the extent and the coherence, the more the IRR tends to be integrated; and (2) the more the IRR is integrated, the greater the potential for an efficient coordination and a sustainable management of the resource (Bolognesi, 2014; Gerber et al., 2009).

\begin{tabular}{cccc}
\hline \hline Types of IRR & & Coherence (between PP instruments and property rights) \\
\hline & & Weak & Strong \\
\multirow{2}{*}{ Extent (nb of uses regulated) } & Narrow & No & Simple \\
& Large & Complex & Integrated \\
\hline
\end{tabular}

Table 1: Typology of Institutional Resource Regimes (IRR), from (Varone and Nahrath, 2014, p.244)

In this context, we define an institutional complexity trap (ICT) as a stage where regime development through new regulatory measures produces less and less additional governance efficiency, and induces failures in the resource regime. Finally, the ICT concept rests on the assumption that most resource regimes' life cycle (dynamic model) follow three stages: emergence (no and simple regime), development (complex regime) and ICT (inability to become an integrated regime) ${ }^{4}$.

\footnotetext{
${ }^{3}$ In this respect, the level of conflicts and the "judicialization" accompanying the implementation of IRR's regulation modes is a good indicator of the existence of incoherencies within a regime, the production of jurisprudence being a way of (temporarily) reducing the frictions or contradictions between the different sets of rules.

${ }^{4}$ For a matter of simplicity, we assume in this paper that the life cycle follows linearly these three stages. This assumption is strengthened by the fact that most of historical perspectives on IRR draw on the following pathway:
} 
In order to conceptualize resource regime dynamics using an IRR perspective we consider that integration is a sigmoidal function of extent (Figure 1). For extent $r \geq 0$, integration of the regime $\mathrm{i}$ in time $\mathrm{t}$ is:

$$
I_{i, t}=\frac{1}{1+e^{\frac{1}{r}}}
$$

Blue curve depicts the life cycle of the regime and its four stages. We also consider I' as the marginal impact of extent on integration (red curve):

$$
I_{i, t}^{\prime}=\frac{e^{\frac{1}{r}}}{r^{2}\left(e^{\frac{1}{r}}+1\right)^{2}}
$$

During the regime development stage, new regulatory measures may prove to be powerful in enhancing regime integration. But then, after the threshold $\mathrm{z}$ where $I^{\prime \prime}(r)=0$, marginal impact of new regulatory measures on integration decreases. This threshold is defined by:

$$
z^{*} \text { where } I^{\prime \prime}(r)=0
$$

The limit of the marginal impact of extent on integration as extent approaches infinity is 0 . This characteristic locks resource regimes in an institutional complexity trap. In other words, if $I_{i, t}$ is concave and $\lim _{r \rightarrow \infty} I_{i, t}^{\prime}=0$, then the resource regime dynamics tends to an ICT. Two questions rise from this setting:

1. Do environmental regimes always tend to fall in institutional complexity trap (blue curve)?

2. What factors could explain the decreasing marginal impact of extent on integration (red curve)?

no, simple, complex regime. Nevertheless, a non-linear sequence is not out of the possibility. 


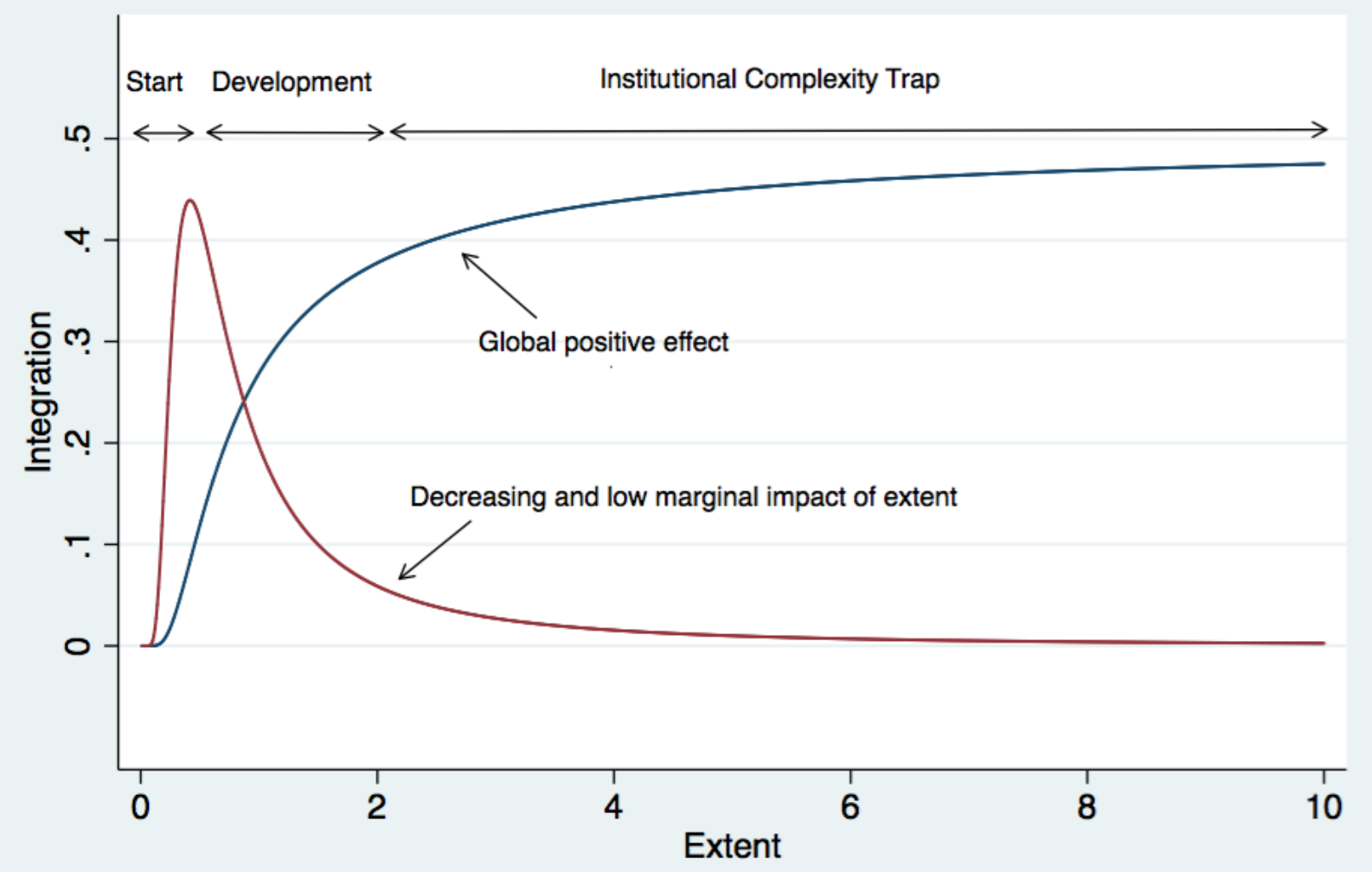

Integration

Marginal integration

Figure 1: Regime integration process and the Institutional Complexity Trap

Based on this conceptual framework, we argue the threshold $r=z$ marks the turning point where loss of coherence due to extension is greater than the direct gain of integration due to extension (Figure1). Regulatory measures are made of public policies (PP) and property rights $(\mathrm{PR})$ and integration depends on the extent $(\mathrm{E})$ and coherence $(\mathrm{C})$ of these regulatory measures. Therefore, considering $I=f(r)$ and $r=P P+P R$, we assert $I=E(P P, P R) \cdot C(P P, P R)$. We know from the IRR framework that there are three types of coherencies: Internal to public policies, internal to property rights and external (crossing public policies and property rights). Consequently $C(P P, P R)=\alpha \cdot P P+\gamma \cdot P R+\sigma \cdot(P P \cap P R)$ and we define integration of the regime i regulating the resource $\mathrm{j}$ as following:

$$
I_{i}=\left(P P_{j, i}+P R_{j, i}\right) \times\left[\alpha . P P_{j, i}+\gamma \cdot P R_{j, i}+\sigma \cdot\left(P P_{j, i} \cap P R_{j, i}\right)\right]
$$

Considering that liberal democratic western societies have developed, since more than two centuries, rather stable institutions as well as efficient corpuses of formal/legal rules of law, we assume that internal coherence of both property rights systems $(\mathrm{PR})$ and public policies $(\mathrm{PP})$ is rather high 
(Crombrugghe and Farla (2012), World Bank Worldwide Governance Indicators). We thus focus our attention on the joint effects of PR (private law) and PP (public law) regulatory measures. We suppose $\alpha$ and $\gamma$ equal to 1 , at least invariant on short term and $\sigma .\left(P P_{j, i} \cap P R_{j, i}\right)$ the trigger of the ICT. The dynamics leading to ICTs are the following: the higher the extent, i.e. $\sum P P_{j, i}, P R_{j, i}$, the lower the $\sigma$, when $r \geq z^{*}$. In the same time increase of $\left(P P_{j, i} \cap P R_{j, i}\right)$ accelerates the process.

\subsection{Hypothesis}

An ICT relates to the reinforcement of the negative joint effects of private and public regulatory measures during extension of the resource regime. We explore how the historical development of natural resource governance tends to lead to an institutional complexity trap therefore limiting a resource regimes' efficiency. In order to answer question number 1, our first hypothesis is empirical and leads to a better description of the institutional complexity trap phenomenon. We assume that, from the threshold $r=z^{*}$, increase of extent produces more and more external incoherencies conducing to an institutional complexity trap. The first hypothesis is about the intuition of the model: the institutional dynamics leading to an ICT.

Hypothesis 1: Extension of the regime leads to an institutional complexity trap by increasing friction in between regulation modes.

Our second hypothesis is more theoretical and relates to the factors causing these frictions in regard to question 2 . In reference to the existing literature, we postulate that regulatory measures are imperfect and produce unexpected outputs due to transaction costs (Coase, 1960; McCann et al., 2005; Williamson, 2000). On this basis, we explore the plausibility of specific transaction costs occurring between regulation modes due to the dynamics of governance. Recent literature focuses on the impact of transaction costs on environmental governance (Barbier, 2011; Coggan et al., 2010; Marshall, 2013; McCann et al., 2005). Nonetheless, unlike the IRR approach, most of the authors focus on specific measures, comparing efficiency of alternatives which do not take into account the interrelations across regulatory measures over different resource uses (i.e. extent). Such a perspective occults the issue of external coherence, $\sigma .\left(P P_{j, i} \cap P R_{j, i}\right)$. Our aim is to fill in this gap by defining transversal transaction costs (TTC) that are specific to interdependant regulatory measures. We are thus assuming that these TTCs are the main drivers of resource regimes' external (in)coherencies, explaining frictions as well as regulatory inefficiencies.

Hypothesis 2: Transversal transaction costs are key drivers of the exacerbation of frictions in between regulation modes, resulting from the extension of the regime

These two hypotheses should help understand the rationale (i.e. factors and causal relationships)

leading to the emergence of an institutional complexity trap. To address them, we combine (and 
strengthen) the IRR framework with some additional New Institutional Economics (NIE) concepts. Whereas the IRR framework's strength lies in is its capacity to describe the structure and evolution of environmental regulations (hypothesis 1) it does not however provide a conceptual model able to explain them (Bolognesi, 2014; Bréthaut and Pflieger, 2015; Gerber et al., 2009; Varone and Nahrath, 2014). By focusing on institutional dynamics, institutional economics provide useful supplementary conceptual tools for identifying mechanisms at work (Barbier, 2011; Ménard, 2011; van den Bergh et al., 2011). Figure 2 synthesizes our explanatory model and approach: an increase of regulatory measures has an ambiguous effect on regime integration. On the one hand, as literature shows, it has a positive impact by developing and refining coordination. On the other hand, a negative and non-expected impact occurs because of frictions across regulatory modes. Hypothesis 1 states that this second effect is reinforced as the resource regime extends, which leads to an ICT. Hypothesis 2 supports hypothesis 1 by infering a theoretical and micro-level explanation of this process: TTC cause frictions across regulatory modes.

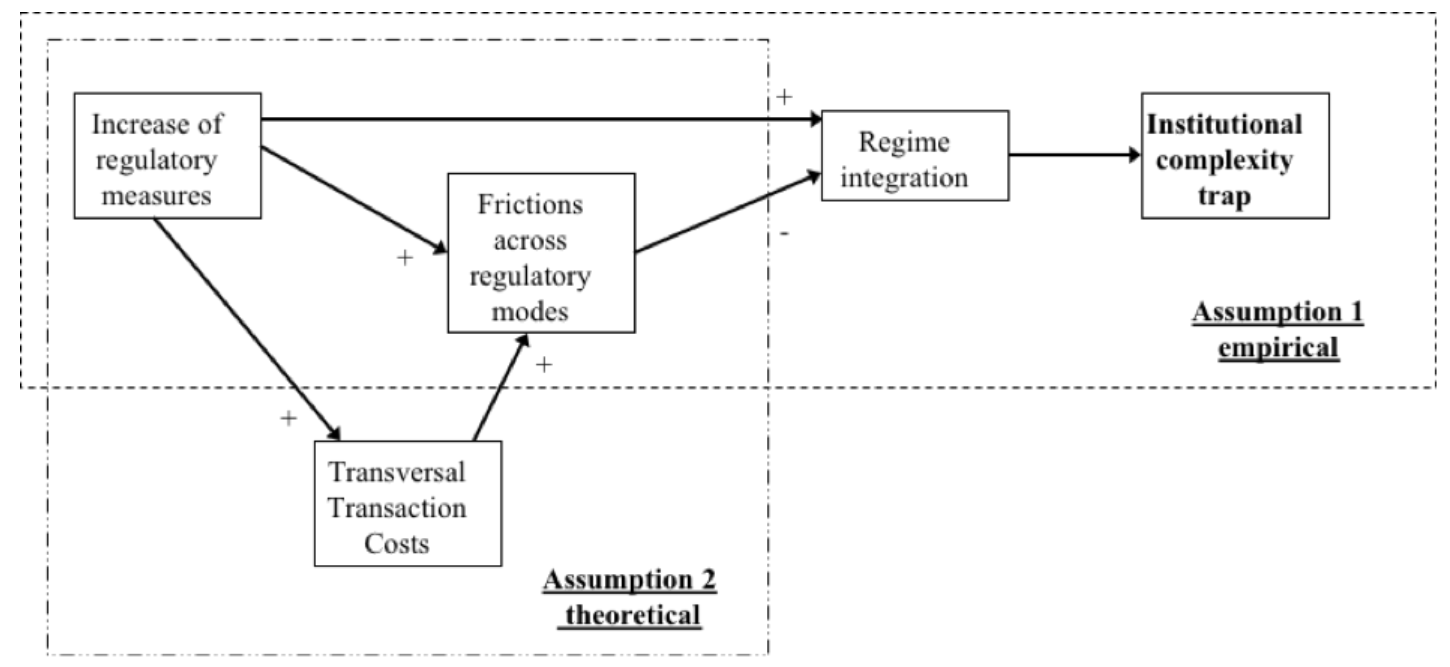

Figure 2: An explanatory model of the Institutional complexity trap

\section{Methodology to characterize an institutional complexity trap}

To validate our hypotheses three types of evidences are needed:

1. Observation of ICT stages in the long term at the scale of various resource regimes;

2. Identification of institutional interplay within resource regimes dynamics that cause occurrences of frictions;

3. A theoretical mechanism capable of explaining these frictions. 


\subsection{Data on Institutional Complexity Trap}

To observe ICTs, we focus on the evolution of extent and integration of resource regimes on the long run. Because extent and integration are difficult to measure compilation of a a large dataset is unfeasible, we choose to score integration and extent from well-informed historical perspectives on resource regimes. Selected cases relate to water regulation in the Netherlands, France, Belgium, Switzerland, Italy and Spain from a period of emergence to recent days. They cover a large time span from 1750 to 2004. These cases have been selected because they have been carried out with the same methodology (Kissling-Näf and Kuks, 2004) and patterns of change are well-documented in the literature ${ }^{5}$. The different authors have identified five stages of extent and integration for each country, except in the Netherlands (6 stages). Scores are linear and go from 0 to 10 (Tables 2 and $3)$. It is worth mentioning that authors accurately described and defined integration which enables us to code a low, medium or high subcategory for each IRR stage. Whereas case studies analyse extent and integration separately, the added-value of our methodology consists in the comparison of these two institutional features. We then argue on the existence of the ICT by comparing linkages between these two attributes within the six resource regimes.

\begin{tabular}{cc}
\hline \hline Score & Integration \\
\hline 0 & Non existent \\
1.25 & Low simple \\
2.5 & Simple \\
3.75 & High simple \\
6.25 & Low complexity \\
7.5 & Complexity \\
8.75 & High complexity \\
10 & Integrated \\
\hline
\end{tabular}

Table 2: Scoring of integration

\begin{tabular}{cc}
\hline \hline Score & Extent \\
\hline 0 & No \\
2.5 & Low \\
5 & Average \\
8.5 & High \\
10 & Full \\
\hline
\end{tabular}

Table 3: Scoring of extent

\subsection{Data on micro-institutional dynamics}

To demonstrate how micro-institutional dynamics correspond to the growth of external incoherence, focus is put on interactions among the four existing regulatory modes which informs us on

\footnotetext{
${ }^{5}$ Among others, literature for the Netherlands (Kuks, 2004), France (Bolognesi, 2018), Belgium (Aubin and Varone, 2001), Switzerland (Varone et al., 2002) and Spain (Swyngedouw, 2014)
} 
the behaviour of both terms in $\sigma .\left(P P_{j, i} \cap P R_{j, i}\right)$. We illustrate such interactions by exploring case studies in European countries. Finally, to pave explanatory avenues for ICT emergence, we develop on the literature of transaction costs related to natural resources governance (Garrick et al., 2013; Krutilla and Alexeev, 2014; McCann, 2013; Phan et al., 2017) and highlight the potential for an unidentified type of transaction costs.

Additionally, we give an specific example of how extent and coherence evolve over time by focusing on one policy issue in water governance, namely flood risk management in Switzerland. Switzerland has a long history of floods and related policies due to its alpine location, precipation patterns, and geomorphology. In our dataset, we cover 169 years of flood-related policies, i.e., since the foundation of the Confederaton in 1848. More precisely, we draw on two datasets: one for extend and one for coherence.

In the dataset on policy extent, we inventorized all flood-related policy instruments adopted in Switzerland between 1848 and 2017 on the national level. We define policy instruments as single means introduced to achieve the goal of flood risk management. Examples of policy instruments include bans on deforestation, requirements for protective flood constructions, land-use plans, hazard maps, or water body maintenance. In order to identify flood relevant laws and instruments, we drew upon existing government reports (FOEN 2013; FOWG 2002; FOWG 2001) and research (Schnitter 1992; Zaugg and Stern 2006), and analyzed Swiss legislation (legal texts are online available at www.admin.ch or on www.lexfind.ch). Thereby, we discerned 92 measures in 19 flood-relevant laws or ordinances on the national level. Laws and ordinances usually adopt, amend, dismantle several flood-related instruments at different points in time. In our dataset, the points in time correspond to the year in which a specific flood instrument has been adopted in a law or ordinance. We categorized the 92 policy instruments into seven policy approaches of flood risk management: (1) Emergency/Civil Protection, (2) Environmental protection, (3) Infrastructure, (4) Insurance, (5) Maintenance, (6) Monitoring, and (7) Spatial planning. In sum, the dataset on policy extent includes 92 observations of single flood instruments, and variables about the adoption year and the approach of each policy instrument.

The dataset on policy coherence in Swiss flood risk management is an independent dataset from the one on policy extent. With coherence we capture the degree to which different laws (or ordinances) regulate flood-related issues in common, thereby creating an integrated governance framework. Spatial planning, for example, is a flood-related issue that is regulated in the Swiss Spatial Planning Act and in the Swiss Hydraulic Engineering Act. Both acts co-regulate spatial planning as an explicit measure of flood risk management and thereby promote the integration of flood risk management across policy sectors. To assess the degree of governance integration, we systematically coded the occurence of flood-related issues in the previously mentioned 19 nationallevel laws. We selected 11 issues which are relevant for flood risk management from a complete list 
of political issues in Swiss water governance (see 4 for an overview).

\begin{tabular}{|c|c|}
\hline Issues & 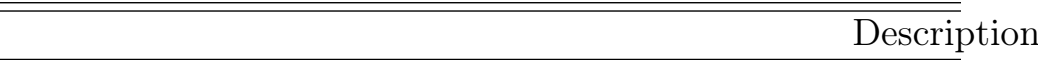 \\
\hline Habitat loss & $\begin{array}{l}\text { Loss or degradation of aquatic habitats (can occur for example } \\
\text { due to the construction of flood prevention measures such as } \\
\text { dams) }\end{array}$ \\
\hline Delimitation of watercourse corridors & $\begin{array}{l}\text { Watercourse corridors (Gewässerraum) refer to the legal con- } \\
\text { cept of the space around a waterbody intended to protect the } \\
\text { waterbody from e.g. degradation due to construction activi- } \\
\text { ties. }\end{array}$ \\
\hline Hydropower operation impacts & $\begin{array}{l}\text { The operation of hydropower facilities has consequences for } \\
\text { floodwater prevention, for example due to the retention capac- } \\
\text { ities of dams built for hydropower generation }\end{array}$ \\
\hline Revitalization & $\begin{array}{l}\text { Revitalization measures (the restauration of rivers to what is } \\
\text { perceived to be a more natural state) can increase retention } \\
\text { capacities of rivers, but can also lead to conflicts with technical } \\
\text { protection measures. }\end{array}$ \\
\hline Biotope conservation & $\begin{array}{l}\text { Refers to the conservation of biotopes for e.g. amphibians Dam } \\
\text { safety Ensuring the safety of large dams constructed for hy- } \\
\text { dropower prevention. }\end{array}$ \\
\hline Drainage planning & Relates to municipal water management \\
\hline Flood risk maps & $\begin{array}{l}\text { Refers to both the creation of flood risk maps and keeping them } \\
\text { up to date }\end{array}$ \\
\hline Lake regulation & $\begin{array}{l}\text { Regulation of water levels in Swiss lakes plays an important } \\
\text { role in attenuating the impacts of floods, but faces trade-offs } \\
\text { regarding the impacts of lake level changes on ecosystems and } \\
\text { shipping. }\end{array}$ \\
\hline Flood protection concept & $\begin{array}{l}\text { Overall, more general plans and strategies regarding flood pro- } \\
\text { tection }\end{array}$ \\
\hline Technical flood protection & $\begin{array}{l}\text { Installation and servicing of measures such as dams or sediment } \\
\text { traps. }\end{array}$ \\
\hline
\end{tabular}

Table 4: Flood-related issues included in the study

More precisely, we systematically annotaded each article in the 19 laws whenever the article regulates one or more of the 11 flood-related issues. The resulting dataset tells us how many issues each law regulates. In a next step, we analyzed which laws regulate issues in common. To this end, we transformed the law-issue data into a law-law matrix, in which the entries count the number of issues co-regulated by each pair of laws at a certain point in time. Time points account for the years in which a new law was introduced, or more specifically, in which a new flood-relevant policy instrument was introduced in a law (e.g. a new law could be introduced in the year 2000, but the flood-relevant instrument of this law could be introduced only ten year later in 2010; we would then take the year 2010 as reference point). In sum, our observations in the policy coherence dataset represent law-law dyads, or pairs of laws. Ties between laws are constructed by counting the number of flood-related issues that both laws co-regulate. 


\section{Characterising ICTs: a diversity of paths}

\subsection{Evidences from long term macro-dynamics: path to ICT}

Increasing the number of regulatory measures does not systematically lead to better governance. Scholars figured out three main causes of these inefficiencies: complexity related to norm multiplication (Bolognesi, 2014; McCann, 2013; Ostrom, 2009), misfits between tools and goals (Renou, 2017; Teisman and Edelenbos, 2011), remaining (behavioural) uncertainty (Bakker, 2010; Marshall, 2013; Spiller, 2013).

On the long run, we observe a global increase in the integration of water regimes from nonexistent to highly complex forms (Figure 3$)^{6}$. Water regime in Italy, Spain and Switzerland started integrating during the second part of the $19^{t h}$ century and then evolved regularly. Belgian, Dutch and French regimes developed since the middle or the late $18^{\text {th }}$ century. Whereas Dutch governance integration was progressive, it was marked by a pause from 1850 to 1900 in the Belgian and French processes. After this pause they both followed the same pattern as Italy, Spain and Switzerland. Regarding extent, the six regimes extend in the long term (Figure 4). Regarding extent dynamics, the same two groups appear. Belgian, Dutch and French regimes known longer and earlier pause (1850-1900) than in the three others (1900-1925). Since about 1950, extent of all water regimes has accelerated, except in Spain. The analysis of the European water regulation shows the same dynamics (Bolognesi, 2014), suggesting it is a structural pattern.

\footnotetext{
${ }^{6}$ Figures 3, 4, and 5 present evolution of IRR with a smoothed view for the sake of readability and coherence in regard to our proposition. Raw data representation draws a stepped curves which does not correspond to reality. Institutional dynamics are mainly incremental, meaning that extent and integration perpetually evolve. By smoothing trends of these institutional features, we aim at emphasising the idea that institutional dynamics are a continuous process. Grey area represents uncertainty of adjustment.
} 


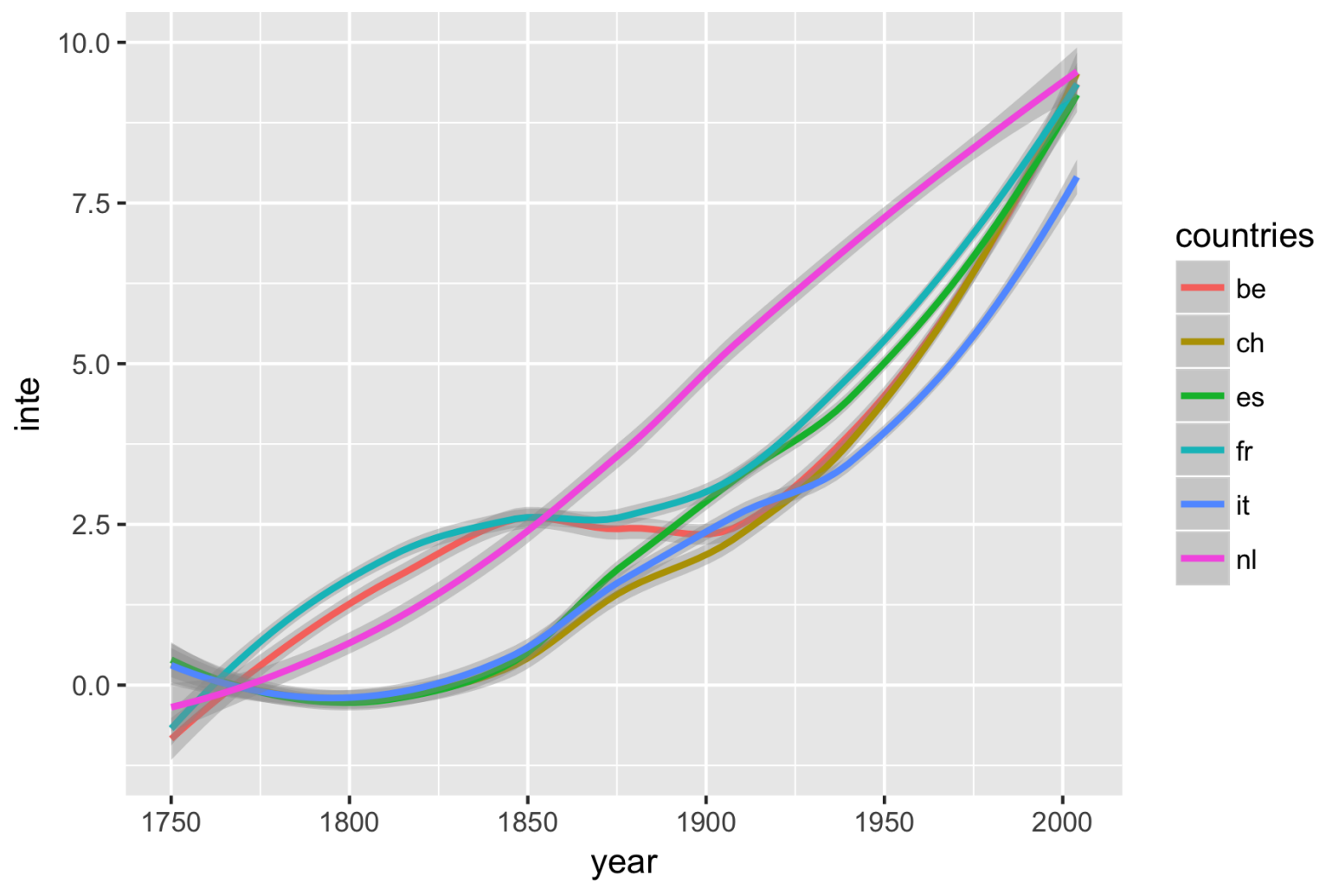

Figure 3: Long run evolution of integration in water regimes 


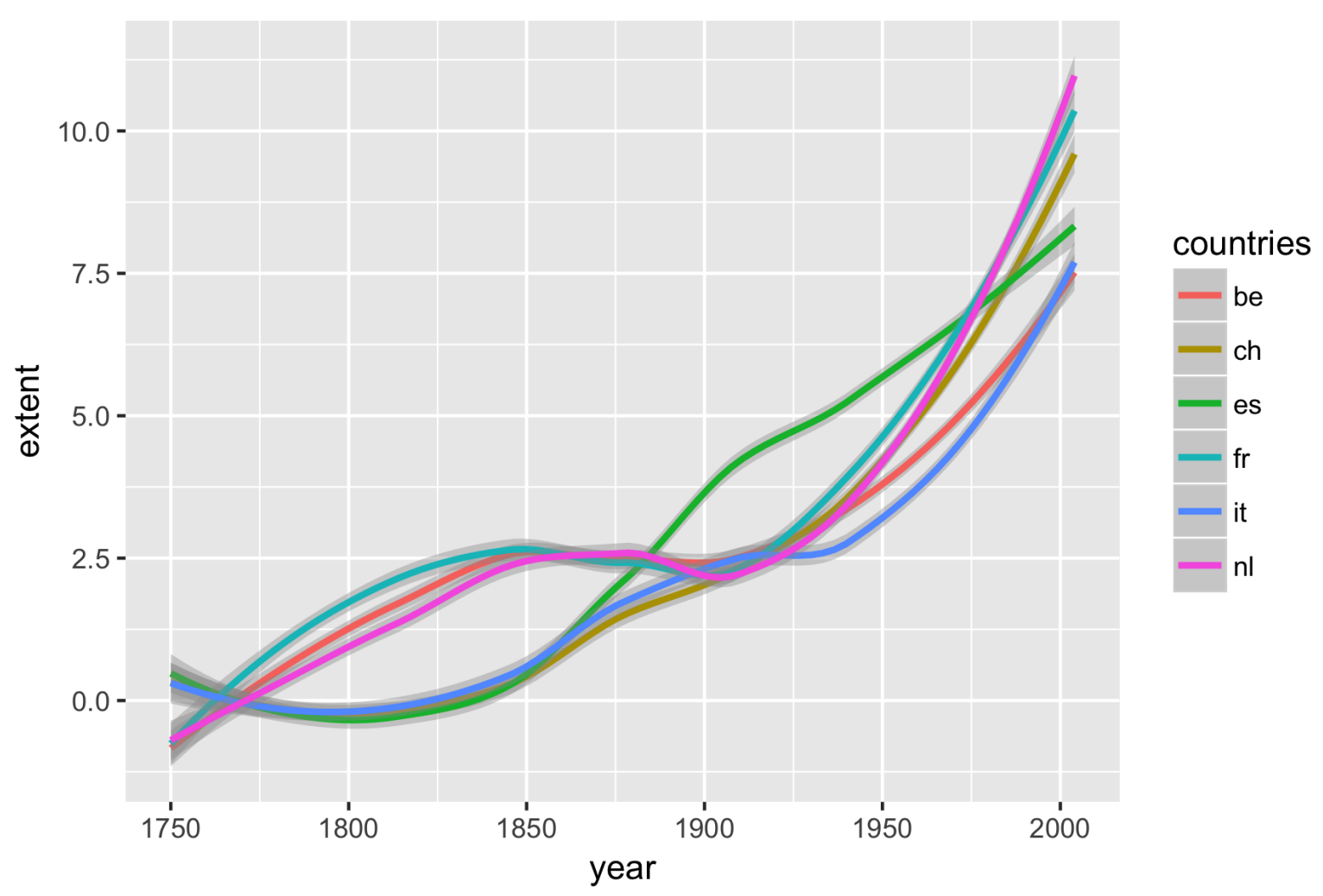

Figure 4: Long run evolution of extent in water regimes

Three salient facts come up when observing the relationship between extent and integration (Figure 5). First, as carried-out by previous studies, extent and integration go on the same way, which means that producing formal institutions contributes to enhancing governance efficiency (Gerber et al., 2009; Nahrath and Bréthaut, 2016; Varone and Nahrath, 2014). Second, a low level of integration corresponds to a short stagnation in the extent process ${ }^{7}$. Third, when extent reaches high levels, integration processes dramatically slow down. This offers evidence for the existence of the ICT: when highly developed, environmental governance falls into an institutional complexity trap that prevents increase in governance efficiency.

Water governance in European countries stood on the delineation between public and private waters during the end of the $19^{\text {th }}$ century (Kissling-Näf and Kuks, 2004; Varone et al., 2002). At the time, public policies filled in governance gaps by refining the definition of property rights and entering new uses into the domain of regulation. The main areas of concern were health, agriculture, urban water and hydroelectricity. Lately (1970-1980), environmental concerns have been integrated into the governance, notably polluter payements, as well as integrated water resource management principles (Andersen, 1999; Correljé et al., 2007). Integration of water regimes in Europe were not significantly enhanced until the 1980ies as a consequence of frictions between the different regula-

\footnotetext{
${ }^{7}$ This is partly due to our methodology which smoothes the curves, assuming that evolution is continuous not stepped.
} 
tory measures (Bolognesi, 2014). Furthermore, the low quality of water bodies' as well as the lack of investment in water utilities suggest that European water governance fails short in expectation. European water regimes are thus locked in an institutional complexity trap and debates on more efficient scales to govern illustrate both the occurrence of ICTs and the willingness to exit them (Guerrin et al., 2014).

In sum, in the long term, we observe an exponential increase of regulatory measures while integration processes have slowed down over the past decades. Integration evolution is not linear, it proceeds as following: 1 / weak increase $2 /$ strong increase $3 /$ very-weak increase/slight decrease ${ }^{8}$. The observed evolution informs us on the sequence of changes in IRR types. It shows that the relation between extent and integration across time is non-linear, highlighting the emergence of an ICT. Extension quickly transforms IRRs to a (high) simple form. After a transition time, extension fuels a new integration dynamic toward a complex IRR form. Then, when IRRs take a highly complex form, extension proves inefficient to enhance integration significantly. IRR are lock-in highly complex form, i.e. integration equal to 7.5. The relation between extent and integration become lower and lower and an ICT emerges.

\footnotetext{
${ }^{8}$ Similar dynamics have been identified in other resource regimes such as land (Varone and Nahrath, 2014) or water in mountain areas (Nahrath and Bréthaut, 2016).
} 


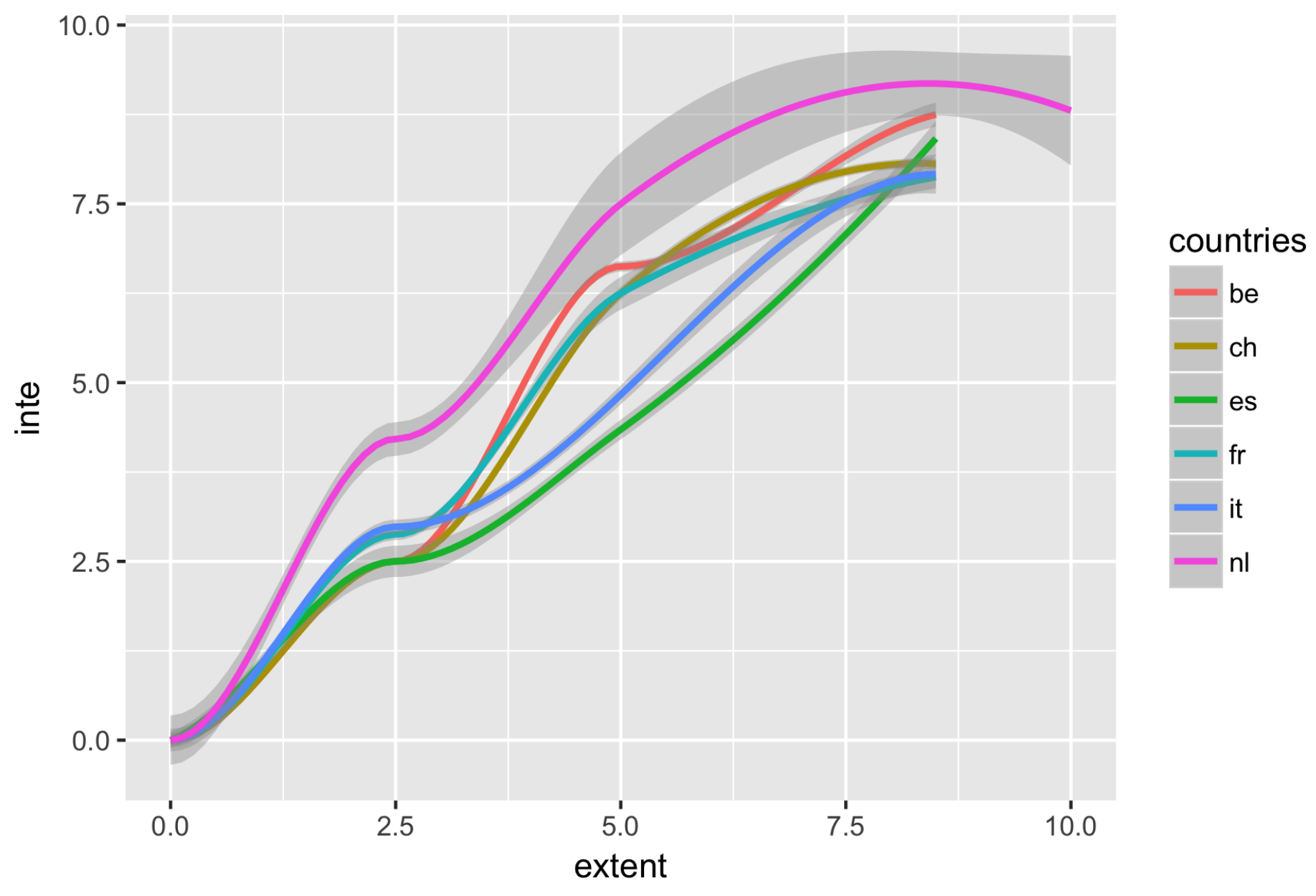

Figure 5: Dynamics of integration regarding extent dynamics

\subsection{Evidences from micro-dynamics: incoherences among regulatory modes}

In order to evaluate the relevance of hypothesis 1, this section presents several empirical examples of regime frictions and incoherencies resulting from the expansion of various resource regimes. It provides evidence for micro-institutional mechanisms that may lead to an ICT. These examples also demonstrate that ICTs may be the result of different types of frictions/incoherencies in between the four regulatory modes, and that, in other words, there are different (extension) dynamics or paths leading to an ICT stage. Table 5 presents the different regulatory modes' interactions, which are of interest to us. We have evacuated two of six conceivable interactions, e.g. modes 2-1 and modes 4-3, because they are unrealistic.

A first and very frequent scenario consists in the increasing contradiction between regulatory modes 2 and 3 resulting from the development of public policies over time which aim at redefining and limiting established property rights. The contradiction between land use planning policy and 


\begin{tabular}{lcccc}
\hline \hline & Mode 1 & Mode 2 & Mode 3 & Mode 4 \\
\hline Mode 1 & $\cdot$ & unlikely & Example 2 & Example 4 \\
Mode 2 & & $\cdot$ & Example 1 & Example 3 \\
Mode 3 & & & $\cdot$ & unlikely \\
Mode 4 & & & &. \\
\hline
\end{tabular}

Table 5: Possible interactions between modes of regulation

land ownership guarantees in Switzerland is a good illustration of such IRR incoherencies leading to ICTs (Varone and Nahrath, 2014). The source of this contradiction is to be found in the social and political compromise, which allowed, in 1969, the establishment of a (new) spatial planning regime attributing new competencies to the federal State as well as to the cantons (these competencies being legally established in the Federal Act on Land Use Planning of 1979). This new (extended) federal regime is based on the attribution of competencies in the domain of land use planning to the federal state, as well as on the constitutional guarantee of ownership and the principle of compensation in the case of significant restriction of use rights (also called "material expropriation" principle) (Varone and Nahrath, 2014, :248). This fundamental contradiction between ownership guarantees (regulation mode 3) and local planning (regulation mode 2) has led to an ICT because it hampered - and is still hampering - the capacity of municipalities to implement local planning in a coherent and restrictive way. This is due to the fact that restrictive zoning, because it entails significant restriction of use rights, often leads to material expropriation and financial compensation to be paid to the landowners. This contradiction has yet to be solved, as the definition of material expropriation is still depending on the jurisprudence of the Federal Court, the judicialization (Rothmayr, 2001) of the IRR implementation process being a typical manifestation of an ICT situation.

A second frequent scenario, refers to the friction or contradiction between regulatory modes 1 and 3. An illustration of this friction or contradiction can be found in the (negative) impacts that various kinds of environmental taxes can have on land value and/or on the utilisation costs of existing use rights ${ }^{9}$. The uncoordinated introduction of federal and cantonal land and equipment taxes in the Canton of Vaud (Switzerland) provides a good example. In 2011, the Canton of Vaud (one of the federated states of the Swiss Confederation) introduced a tax on community facilities ${ }^{10}$ aiming at capturing a part of (private) land added values resulting from (public) land use measures, in order to finance community equipment (public transports, schools, hospitals, public spaces and parks, nurseries, etc.). In 2014, the federal government introduced another tax on the value added to land by the zoning process (in an attempt to fund material expropriations and solve the contradiction we mentioned in scenario 1) which led to a public contestation denouncing a "double taxation" as well as to the Canton's protest (which feared an induced lowering of its own tax). Here too, IRR extension leads to an ICT.

\footnotetext{
${ }^{9}$ e.g. infrastructure or equipment tax, waste water tax, tax on land added land value, soil decontamination tax, Transferable Development Rights (TDR) or CO2 tax.

${ }^{10}$ Articles 4b and sqs of the cantonal law on communal taxes of December 5th 1956 (RSV 650.11).
} 
A third scenario consists of the friction/contradiction between regulatory modes 2 and 4 . The unexpected and contradictory impacts of liberalisation policies on the ownership structure of network industry firms (leading to privatisation/nationalisation processes), which are reducing competition among firms providing goods and services, is a good example of such contradictions. Modernization of urban water governance in EU is a school case of interactions between regulatory modes 2 and 4 . This modernization process consists mainly in liberalizing and re-regulating the sector (Allouche et al., 2008; Bolognesi, 2014; Gee, 2004). It proceeds through regulatory measures of mode 2 such as the directive on the award of concession contracts $(2014 / 23 / \mathrm{UE})$ or the directive on public procurement in network industries (204/25/EU). In consequence, private participation in the sector increases, mainly through PPP (Chong et al., 2015) and corporatization (Klien, 2014; Ménard and Peeroo, 2011). This school case emphasizes how measures on property rights allocation processes (mode 2) interact with property rights owners' identities (mode 4 and produce frictions. In France, one of the most symptomatic frictions is the creation of a new contractual form, e.g. Societé Publique Locale, allowing public owned entities not to comply with competitive regulations. Another one is rooted in the difficulty for local public authorities to carry out these competitive procedures, favouring private actors during contract negotiation. These frictions are to a large extent linked to organizational and institutional issues.

A fourth scenario consists of the friction between regulatory modes $\mathbf{1}$ and $\mathbf{4}$. Modernization of urban water governance stands on New Public Management principles and therefore benchmarking (mode 1) instruments are more and more common (Bolognesi, 2018; Modell, 2009). Following this trend, 17 performance indicators were put in place in France in 2007 under the responsibility of Onema, a kind of regulatory agency for the sector. Recent studies suggest that this public policy conflicts with actual allocation of property rights (mode 4 of regulation). It can conflict with the values of public operators that might be reluctant to be subjected to performance measurement in the case of public service delivery (Renou, 2017; Tsanga-Tabi and Verdon, 2014). Authors argue that in certain cases local actors are not organized in a way compatible with these performance reporting requirements or that these generic indicators do not meet local reality conducing local actors to not take them into account. Others highlight that performance indicators favour private operators because they are used to optimize these metrics (Canneva and Guérin-Schneider, 2011). Exploring the idea of barriers to performance measurement implementation, Bolognesi et al. (2016) pinpoint the large variety of frictions that can rise up. Especially, they provide with evidences of frictions due to technology and path dependency.

In all the four scenarios, one may thus observe how IRR expansion is producing contradictions and incoherencies between property rights systems and public policies as well as increasing frictions between various regulation modes which are contributing to impair/reduce IRR integration and weaken its regulatory efficiency, and finally are leading to ICT situations. Hypothesis 1 is thus 
confirmed.

\subsection{Linking macro and micro dynamics: the increase of institutional overlaps and interplays}

Additionally to international trends in water governance, we zoomed into a specific water governance issue. More precisely, we analyzed the evolution of extent and coherence in Swiss flood risk management over a period of almost 170 years.

Figure 6 shows the evolution of Swiss flood risk management between 1848 and 2017. Since 1848 a total of 92 policy instruments regulating floods have been adopted in the seven colored policy approaches. Initially, flood risk management focused on infrastructure-based approaches (in green). In the 1870ies, floods were attributed to forest clearances. As a consequence reforestation was mandated in the Federal Constitution's article 24 on forest conservation as of 1874 . Moreover, protective forests were introduced together with clearning bans in 1876. Both types of instruments are classified under environmental protection, in yellow in Figure 6. Monitoring instruments, e.g., of water levels, were introduced in the late 19th century and instruments of emergy and civil protection as of 1950ies. Starting in the 1990ies, an exponential growth can be observed with an increase of adopted instruments in all seven sectors of flood risk management, whereby instruments on insurances and water body maintenances were newly introduced. In sum, Figure 6 illustrates that, over time, more and more policy instruments have been adopted in Swiss flood risk management with an almost exponential growth. 


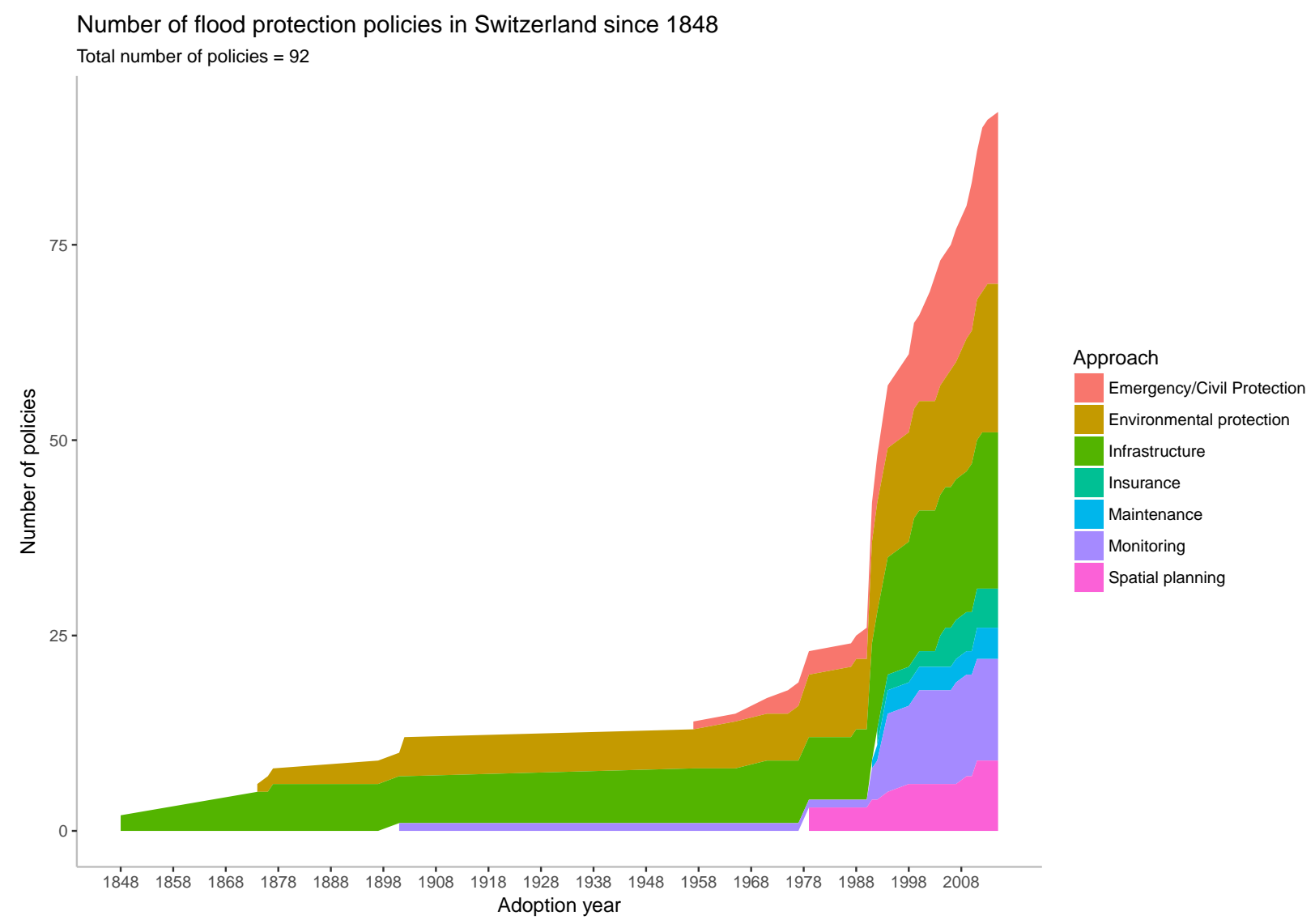

Figure 6: Evolution of extent in Swiss flood risk management (1848-2017), n=92

With more policy instruments, there is a higher need to integrate those instruments increases in order to maintain regime coherence. In Figure 7, we illustrate the increasing necessity to coordinate the diverse issues regulated across laws (or ordinances) in Swiss flood risk management. With issues we mean societal problems related to flood risks that are addressed by means of political solutions. For example, flood risk maps indicate zones of increased flood risk and serve as a spatial planning tool to avoid constructions in flood-prone areas. The need to adopt flood risk maps came up on the political agenda in Switzerland as a flood-related issue, which was then regulated in different acts that specify who, when, and how flood risk maps have to be adopted.

The nodes in Figure 7 represent laws, in which flood-relevant issues have been regulated, ties indicate that a pair of laws co-regulates an issue, and the thickness of ties is proportional to the number of co-regulated issues. For example, the Federal Constitution (BV) was the only act in place that regulated flood protection in 1848. By 1979, the Spatial Planning Act (RPG) introduced floodrelavant issues that the Act co-regulated with the Federal Constitution; and by 1987, the Nature and Cultural Heritage Act (NHG) co-regulated issues with the Federal Constitution and the Spatial Planning Act. Over time, there are more, as well as more thicker ties among laws showing that laws increasingly co-regulate flood-related issues. Cross-references signify that the legal framework 
mandates the integration of issues in flood risk management. Thereby, the legal framework reflects that flood risk management is a complex task, where involved actors have to consider multiple laws and issues referenced in multiple laws. As diverse actors are legally mandated to consider multiple issues across legal acts, their portfolios become increasingly complex and transaction costs of coordination increase as well. In summary, 7 illustrates that the legal framework of Swiss flood risk management mandates an increasing amount of integration over time. For actors involved in policymaking it means that they have to coordinate with other actors and consider multiple issues across sectors, which impacts transaction costs. 


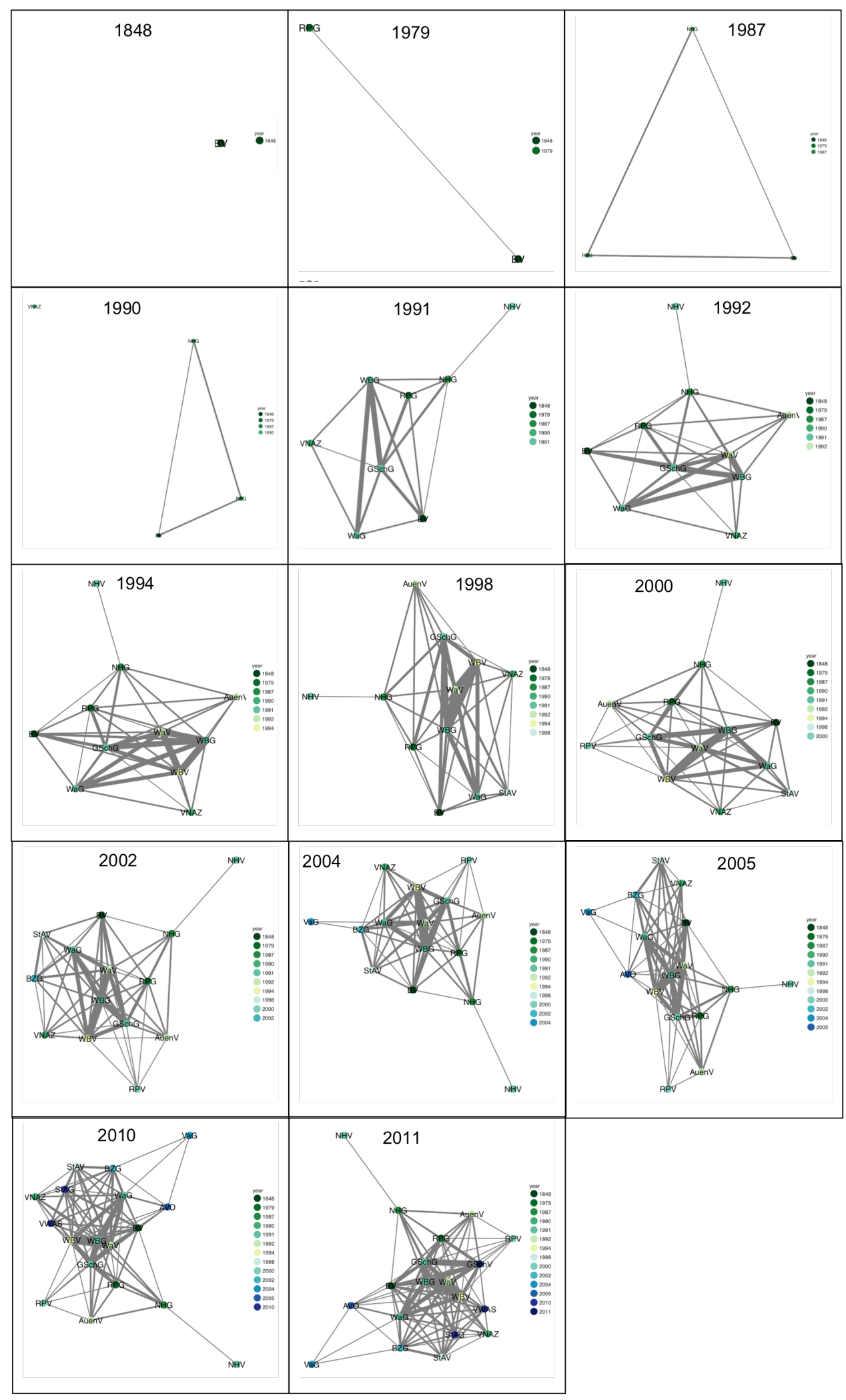

Figure 7: Evolution of integration demand in Swiss flood risk management 


\section{Explaining the ICT: transversal transaction costs beyond sequen- tial transaction costs}

\subsection{Likelihood of TTC}

Our second hypothesis is that a transversal type of transaction cost causes frictions among regulatory measures and modes. We aim to provide explanatory factors of the process leading to ICTs. More specifically, we propose the concept of Transversal Transaction Costs (TTC) in order to explain how $\sigma .\left(P P_{j, i} \cap P R_{j, i}\right)$ contributes to the decreasing marginal impact of extent on integration. As environmental policies and governance are subject to a variety of transaction costs (Garrick et al., 2013; Marshall, 2013), we state that a peculiar type of transaction cost causes ICT.

After transposing Williamsonian analysis to the management of natural resources (Challen, 2000; Hanna, 1995; McCann et al., 2005)), transaction costs and environmental research focus on the life cycle of an environmental policy (Coggan et al., 2010; Finon and Perez, 2007; Krutilla and Krause, 2010; Rendón Thompson et al., 2013). Existing classifications of transaction costs are based on activity, safeguard mechanisms and a given step in policy-making (Challen, 2000; Coggan et al., 2010; Marshall, 2013; McCann et al., 2005). This literature only considers specific programs and does not grasp interdependencies among components of resource regimes. However, by underlining the consequential impacts of extent on external coherence, we show (cf. discussion about hypothesis 1) that interdependencies exist and are significant. Although it seems that specific transaction costs have an impact on institutional interdependencies and create friction, to our knowledge, literature never explores this specific case.

Empirical assessments point out to which extent transaction costs impact resource regime efficiency. These assessments mostly concern the costs of organizing good or service transfers and show that these vary and are of high level (Cheung, 1992). They value time spent by people on "non productive" tasks related to the transaction, such as gathering information or monitoring. A number of authors (Bilodeau et al., 2007; Klien, 2014; Ménard and Peeroo, 2011; Shleifer and Vishny, 1994) point out that policy-induced transaction costs in the case of water transfers in Western USA are highly variable: from $54 \$$ /acre to $187 \$$ /acre. If transaction costs induced by environmental policies vary, it is however known that they are of high level - they contribute to about $15 \%$ of the total cost of supplying a good or a service (Mettepenningen et al., 2009; Phan et al., 2017) - and they alter efficiency of governance. By focusing on private and administrative transaction costs, these studies inform us of the internal coherence of public policies and property rights, e.g. levels $\alpha$ and $\gamma$ in $I_{i}=\left(P P_{j, i}+P R_{j, i}\right) \times\left[\alpha \cdot P P_{j, i}+\gamma \cdot P R_{j, i}+\sigma \cdot\left(P P_{j, i} \cap P R_{j, i}\right)\right]$.

However, these kinds of transaction costs do not inform us on frictions due to regulatory modes

of interaction. By not contributing to determine $\sigma$ in the term $\sigma .(P P \cap P R)$, they give us no insights on the causes of the institutional complexity trap. Nonetheless the various approaches 
of institutional complementarities (Amable, 2016; Aoki, 2007; Höpner, 2005; Jellema and Roland, 2011; Ostrom, 2005; Roland, 2004) prove that institutional linkages are of first interest in showing how a specific type of transaction cost may determine $\alpha$. In this sense, concepts of first order such as economization and institutional embeddedness (Williamson, 2000) point out interactions among institutions. This view does not consider institutions alone but in a pool of pre-existing institutions. This institutional environment is more or less well aligned with the new institution which can help explain patterns of change or stability (North, 2005). Aoki Aoki (2007) develops these ideas in a strategic game of actors, where each actor chooses institutions in order to maximize his utility regarding expected complementaries. If recent research qualifies this as a functionalist perspective, it at least emphasizes the relevance of going further (Amable, 2016). In fact, if complementaries can strengthen an institutional configuration they can weaken it too (Amable, 2016).

We consider that institutional complementaries must not only be studied in their positive but also in their negative impacts. Whereas positive impacts have been widely studied by assuming functionalist dynamics, which leave theory of institutional dynamics unable to explain static frictions. We propose an alternative to, and consistent with, this perspective of institutional change by focusing on negative impacts of institutional complementaries, or more accurately, the emergence of mis-complementarities through Transversal Transaction Costs (TTC). Different feasible combinations of institutions exist which correspond to change in transaction cost structures. This proposition extent the scope of transaction costs economics which grasp internal coherence of institutional regime only.

The TTC concept spreads the Transaction Cost Economics to external coherence. Consequently, TTC leads to conceive institutional complementarity as a gradual feature, not a dichotomous one, and implements it in the current scope of institutional economics. Regarding the institutional dynamics leading to an ICT, TTC can explain the increase of frictions among regulatory modes and the loss of external coherence during the extension of the institutional regime. We define Transversal Transaction Costs (TTC) as the transaction costs occurring when regulatory modes interact. These TTC contribute to the loss of external coherence leading to ICT. In sum, transaction costs cover internal coherence, i.e. $\alpha . P P_{j, i}$ and $\gamma \cdot P R_{j, i}$, while TTC cover external coherence, i.e. $\sigma .\left(P P_{j, i} \cap P R_{j, i}\right)$ our term of interest. Therefore, validating $H_{2}$, the existence of TTC gives micro explanations of the process leading to an ICT $\left(H_{1}\right)$.

\subsection{Specifying TTC: occurrence, perspective, nature and scope}

We identify four dimensions specifying transversal transaction costs (TTC): occurrence, perspective, nature and scope (Table 6). These specifications can help further research to measure TTC.

Occurrence can be ex ante or ex post. It relates to when TTC occurs, before or after implementation of a new regulation mode. Like williamsonian transaction costs, it depends on the degree of 
aversion to uncertainty regarding the cost of developing the institutional matrix (Williamson, 2000). Generally speaking, this point is illustrated by the trade-off between administered or competitionbased regulation. Ex ante TTC entails costs for building and maintaining the administrative body but, in principle, reduces uncertainty. Modes of regulation 1 and 2 produce ex ante TTC because new norms resulting from a control mechanism mostly involve setting up a substantial governance structure (Marshall, 2013; Williamson, 2005). Ex post occurrence costs are costs of adaptation induced by more flexibility. Modes of regulation 3 and 4 are vectors for ex post TTC due to the incompleteness of property rights and require safeguard mechanisms to be deployed.

Perspective can be dynamic or static. Perspective specifies if TTC come from the operating regulation or reforming regulation. This characteristic reflects the stability of the system's current balance and the IRR's capacity for change. This dimension is helpful for thinking of governance in terms of adaptive management (Chaffin et al., 2014; Schultz et al., 2015). As an illustration, regulatory modes 1 and 2 can create dynamic TTC when new norms imply changes in existing property rights structure, like in the example 3.

Nature of TTC refers to components of the IRR and can be institutional, technological or organizational. The institutional origin of transaction costs has been much discussed in the literature; incomplete property rights and imperfect norms stand out among the main factors driving this trend (Coase, 1960). Additionally, overly complex regimes due to the (autonomous) multiplication of bilateral (mode 4) or top-down (mode 2) norms create a sort of "Spaghetti bowl" effect (Bhagwati et al., 1998) exacerbating these TTC. The technological nature is a decisive factor, particularly in network industries (Fuenfschilling and Truffer, 2014; Künneke et al., 2010). Recent trends towards deconcentration and devolution of public command (Ménard and Saleth, 2013) as well as the setting of micro-institutions to create coherence (Ménard, 2009; Saleth and Dinar, 2008) illustrate the organizational nature of TTC.

Scope can be specific or generic. Scope refers to the bodies involved, but also to the content of TTC. Such costs may be due to incoherence between generic components (beliefs, legal modalities, market regulation), e.g. mode 2 , or very specific (contractual provisions, micro-economic characteristics), e.g. mode 4. As seen with example 3, the EU directive on public procurement creates generic TTC. Any attempt to develop the institutional matrix without anticipating new norm interactions is a key fault in the policy design accompanying top-down expansion. In consequence of these TTC, alignment between the various components is mediocre, reducing IRR coherence. Scope must be of first interest when analysing multilevel or polycentric institutional regimes. 


\begin{tabular}{|c|c|c|}
\hline Dimension & Definition & Modalities \\
\hline Occurrence & $\begin{array}{l}\text { Occurrence relates to when TTC occurs, before or } \\
\text { after implementation of new regulation mode. }\end{array}$ & Ex post Ex ante \\
\hline Perspective & $\begin{array}{l}\text { Perspective relates to the running of the IRR ac- } \\
\text { cording to TTC come from operating or changing } \\
\text { regulation. }\end{array}$ & Dynamic Static \\
\hline Nature & Nature of TTC refers to components of the IRR & $\begin{array}{l}\text { Institutional Technological } \\
\text { Organizational }\end{array}$ \\
\hline Scope & $\begin{array}{l}\text { Scope refers to the bodies involved but also the con- } \\
\text { tent of TTC }\end{array}$ & Generic Specific \\
\hline
\end{tabular}

Table 6: Dimensions of transversal transaction costs

\subsection{TTC dimensions and regulation modes' interactions}

To illustrate the relevance of TTC and following the logic of Transaction Cost Economics (Williamson, 2000), we align regulatory modes of interaction with dimensions of TTC (Table 7).

Deriving from example 1, interactions between modes 2 and 3 may have a profile of TTC mostly ex post, static, institutional and generic. In example 1 we observe that land use planning policy in Switzerland creates TTC by being misaligned with ownership guarantees. Therefore restrictive zoning conflicts with financial protection of property rights. These TTC appears after the reform (i.e. introduction of Federal Act on Land Use Planning of 1979) and judicialization illustrates the institutional nature of these TTC. Policy implications are creation of measures to minimize ex post TTC. An option should be to simplify judiciary procedures for this frequent case or to create a hierarchy between these regulatory modes in order to reduce judicialization and to clarify incentives (which should reduce uncertainty and TTC) ${ }^{11}$.

In example 2, interactions between modes 1 and 3 imply a mostly ex ante, static, institutional and generic TTC profile. Institutional and generic dimensions are particularly significant. In this case, frictions come from the multilevel structure of the resource regime because there are no consistent perspectives on incentives in between the different levels. In consequences, this creates unexpected effects on property rights allocation.

Example 3 lets us assume that interactions between modes 2 and 4 correspond to ex ante, institutional, organizational and generic TTC. In this example, we pointed out that the EU directive on public procurement (generic rule) impacts an owners' identity by favouring sizeable operators due to complex measures. The organizational requirements limit ability to participate to the awards.

Regarding example 4, interactions between modes 1 and 4 result in mostly dynamic, technological, organizational and specific TTC. The use of performance indicators (mode 1) impacts on

\footnotetext{
${ }^{11}$ The introduction of a clear and stable definition of material expropriation in the Federal Act on Land use planning could be a way of reducing TTC.
} 
property rights allocation (mode 4) because it implicitly favours certain types of technological and organizational characteristics for urban water services. Administrative support and institutional adaptation for disadvantaged services would help avoid this perverse effect. Implementation generate TTC and their reduction would imply production of meso-institutions (De Castro et al., 2014; Ménard, 2014) ${ }^{12}$.

\begin{tabular}{lllll}
\hline \hline Mode & Occurrence & Perspective & Nature & Scope \\
\hline $1 \& 2$ & & & Unlikely & Generic \\
$1 \& 3$ Example 2 & Mostly ex ante & Static & Institutional & Mostly specific \\
$1 \& 4$ Example 4 & both & Mostly dynamic & Mostly technological and organizational & Generic \\
$2 \& 3$ Example 1 & Mostly ex post & Static & Institutional & Mostly generic \\
$2 \& 4$ Example 3 & Mostly ex ante & both & Mostly institutional and organizational & Monsty \\
$3 \& 4$ & Unlikely & & & \\
\hline
\end{tabular}

Table 7: Likelihood of dimensions of TTC depending on regulatory modes of interaction

\section{Conclusion}

The present paper addresses the issue of the dynamics and the efficiency of resource regimes. It provides explanations on why resource regimes develop in the long term but still fall short of expectations in regard to sustainability. We explore institutional causes of this paradox. It is shown that resource regimes' dynamics tends to be locked in an institutional complexity trap (ICT) due to growing frictions among regulatory modes.

Our first hypothesis emerges from theoretical considerations on institutional dynamics. It tests whether institutional complexity trap emergence is significant. We provide two sorts of empirical evidence to confirm this. First, taking the case of the evolution of European water regime in the long term (1750-nowadays), it is shown that each regime falls in an ICT due to a decreasing marginal impact of regulatory measures on the efficiency of the regime. We demonstrate that the relation between integration of resource regimes and increase of regulatory measures is concave over time. Secondly, we provide complementary evidence by zooming on regulatory modes of interaction in the short term. We emphasize that frictions among them are numerous and various, highlighting the path diversity to ICT. Therefore, the first set of evidence confirms the significance of ICT emergence while the second confirms our hypotheses that frictions among regulatory measures cause this emergence.

Our second hypothesis concerns micro-mechanisms leading to institutional complexity traps. It aims at paving the way for theoretical explanations. We assume that a new form of transaction cost is crucial to understand frictions among regulatory modes: Transversal Transaction Costs (TTC).

\footnotetext{
${ }^{12}$ Meso-institutions are "the connective tissue which cross-links levels of the environment and shape the context in which entrepreneurs make decisions" (De Castro et al., 2014, p.75).
} 
We define them and discuss their characteristics through four different dimensions (occurrence, perspective, nature and scope). Their identification within four cases gives us insights on their concrete operation.

This paper contributes to the analysis of the dynamics of natural resource governance. Demonstration of the existence of an ICT opens the floor to original theoretical and empirical discussions and findings. On the theoretical side, ICT dynamics, through its cumulative perspective, provides an alternative and complementary story to the evolutionary interpretation of institutional dynamics, assuming a Darwinist process in institutional change (Hodgson and Knudsen, 2010).Evolutionary interpretation argues that institutions follow a selection process whereby efficient institutions substitute the others. The question is whether these two theoretical models explain different cases or if they are embedded. In which case do resource regimes follow ICT or evolutionary dynamics? Are resource regime dynamics evolutionary on the mid-term at the scale of individual institutions and cumulative in the long term at the scale of the regime? Regarding empirical study of natural resource dynamics, our identification of an ICT gives us new insights on direct and indirect impacts of new regulatory measures. It emphasizes that indirect negative effects may have been underestimated and that taking into account transversal transaction costs should significantly change results. Moreover we suggest that, due to the decreasing marginal impact of extent on integration, from a certain stage of development, resource regimes would gain in reforming their structure rather than keeping on developing and increasing regulatory tools. This echoes the literature on integrated water resource management (Biswas, 2004) or Nexus (Scott et al., 2011) in the literature of resource management. The question is to what extent does opening the scope of governance, by being multisectoral or multifunctional, increase sustainability?.

\section{References}

Allouche, J., Finger, M., and Luís-Manso, P. (2008). Water sector evolution scenarios: the case of Europe. Water Policy, 10(3):221-238.

Amable, B. (2016). Institutional complementarities in the dynamic comparative analysis of capitalism. Journal of Institutional Economics, 12(1):79-103.

Andersen, M. S. (1999). Governance by green taxes: implementing clean water policies in Europe 1970-1990. Environmental Economics and Policy Studies, 2(1):39-63.

Aoki, M. (2007). Endogenizing institutions and institutional changes. Journal of Institutional Economics, $3(1): 1-31$.

Aubin, D. and Varone, F. (2001). La gestion de l'eau en Belgique. Analyse historique des régimes institutionnels (1804-2001). Courrier hebdomadaire du CRISP, 26(1731-1732):5-75.

Bakker, K. (2010). Privatizing Water: Governance Failure and the World's Urban Water Crisis. Cornell University Press, Ithaca, NY. 
Bamberg, S. and Möser, G. (2007). Twenty years after Hines, Hungerford, and Tomera: A new meta-analysis of psycho-social determinants of pro-environmental behaviour. Journal of Environmental Psychology, $27(1): 14-25$.

Barbier, E. B. (2011). Transaction costs and the transition to environmentally sustainable development. Environmental Innovation and Societal Transitions, 1(1):58-69.

Bhagwati, J., Greenaway, D., and Panagariya, A. (1998). Trading Preferentially: Theory and Policy. The Economic Journal, 108(449):1128-1148.

Bilodeau, N., Laurin, C., and Vining, A. (2007). "Choice of Organizational Form Makes a Real Difference": The Impact of Corporatization on Government Agencies in Canada. Journal of Public Administration Research and Theory, 17(1):119-147.

Biswas, A. K. (2004). Integrated Water Resources Management: A Reassessment. Water International, 29(2):248-256.

Bolognesi, T. (2014). The paradox of the modernisation of urban water systems in Europe: Intrinsic institutional limits for sustainability. Natural Resources Forum, 38(4):270-281.

Bolognesi, T. (2018). Modernization and Urban Water Governance: Organizational Change and Sustainability in Europe. Palgrave Macmillan UK, London.

Bolognesi, T., Brochet, A., and Renou, Y. (2016). Assessing resistance to public policy tools: insights from water performance indicators in the Grenoble area (France). SSRN Working Paper, 2960134.

Bromley, D. J. (1991). Environment and economy: property rights and public policy. Blackwell, Oxford.

Brousseau, E., Garrouste, P., and Raynaud, E. (2011). Institutional changes: Alternative theories and consequences for institutional design. Journal of Economic Behavior \& Organization, 79(1-2):3-19.

Bréthaut, C. and Pflieger, G. (2015). The shifting territorialities of the Rhone River's transboundary governance: a historical analysis of the evolution of the functions, uses and spatiality of river basin governance. Regional Environmental Change, 15(3):549-558.

Canneva, G. and Guérin-Schneider, L. (2011). National monitoring of water utility performance in France. Water Science \& Technology: Water Supply, 11(6):745.

Chaffin, B. C., Gosnell, H., and Cosens, B. A. (2014). A decade of adaptive governance scholarship: synthesis and future directions. Ecology and Society, 19(3).

Challen, R. (2000). Institutions, transaction costs, and environmental policy: institutional reform for water resources. Edward Elgar Publishing.

Cheung, S. N. (1992). On the new institutional economics. In Contract Economics. Blackwell.

Chong, E., Saussier, S., and Silverman, B. S. (2015). Water Under the Bridge: Determinants of Franchise Renewal in Water Provision. The Journal of Law, Economics, and Organization, 31(1):3-39.

Cleaver, F. (2002). Reinventing Institutions: Bricolage and the Social Embeddedness of Natural Resource Management. The European Journal of Development Research, 14(2):11-30. 
Coase, R. H. (1960). The Problem of Social Cost. The Journal of Law $\&$ Economics, 3:1-44.

Coggan, A., Whitten, S. M., and Bennett, J. (2010). Influences of transaction costs in environmental policy. Ecological Economics, 69(9):1777-1784.

Correljé, A., François, D., and Verbeke, T. (2007). Integrating water management and principles of policy: towards an EU framework? Journal of Cleaner Production, 15(16):1499-1506.

Crombrugghe, D. d. and Farla, K. (2012). Preliminary conclusions on institutions and economic performance. MERIT Working Paper 035, United Nations University - Maastricht Economic and Social Research Institute on Innovation and Technology (MERIT).

De Castro, J. O., Khavul, S., and Bruton, G. D. (2014). Shades of Grey: How do Informal Firms Navigate Between Macro and Meso Institutional Environments? Strategic Entrepreneurship Journal, 8(1):75-94.

Finon, D. and Perez, Y. (2007). The social efficiency of instruments of promotion of renewable energies: A transaction-cost perspective. Ecological Economics, 62(1):77-92.

Fuenfschilling, L. and Truffer, B. (2014). The structuration of socio-technical regimes - Conceptual foundations from institutional theory. Research Policy, 43(4):772-791.

Garrick, D., McCann, L., and Pannell, D. J. (2013). Transaction costs and environmental policy: Taking stock, looking forward. Ecological Economics, 88:182-184.

Gee, A. (2004). Competition and the water sector. Antitrust, 2:38-40.

Gerber, J.-D., Knoepfel, P., Nahrath, S., and Varone, F. (2009). Institutional Resource Regimes: Towards sustainability through the combination of property-rights theory and policy analysis. Ecological Economics, 68(3):798-809.

Guerrin, J., Bouleau, G., and Grelot, F. (2014). "Functional fit" versus "politics of scale" in the governance of floodplain retention capacity. Journal of Hydrology, 519(C):2405-2414.

Hanna, S. (1995). Efficiencies of user participation in natural resource management. In Property Rights and the Environment: Social and Ecological Issues, pages 59-67. World Bank Publications, Washington.

Hodgson, G. M. and Knudsen, T. (2010). Darwin's conjecture: The search for general principles of social and economic evolution. University of Chicago Press.

Höpner, M. (2005). What connects industrial relations and corporate governance? Explaining institutional complementarity. Socio-Economic Review, 3(2):331-358.

Jellema, J. and Roland, G. (2011). Institutional clusters and economic performance. Journal of Economic Behavior \& Organization, 79(1-2):108-132.

Kaika, M. and Page, B. (2003). The EU Water Framework Directive: part 1. European policy-making and the changing topography of lobbying. European Environment, 13(6):314-327.

Kissling-Näf, I. and Kuks, S., editors (2004). The Evolution of National Water Regimes in Europe. Springer Netherlands, Dordrecht. 
Klien, M. (2014). Corporatization and the Behavior of Public Firms: How Shifting Control Rights Affects Political Interference in Water Prices. Review of Industrial Organization, 44(4):393-422.

Knight, J. (1992). Institutions and Social Conflict. Cambridge University Press.

Krutilla, K. and Alexeev, A. (2014). The Political Transaction Costs and Uncertainties of Establishing Environmental Rights. Ecological Economics, 107:299-309.

Krutilla, K. and Krause, R. (2010). Transaction Costs and Environmental Policy: An Assessment Framework and Literature Review. International Review of Environmental and Resource Economics, 4:261-354.

Kuks, S. M. M. (2004). Water governance and institutional change. PhD thesis, University of Twente, Enschede.

Künneke, R., Groenewegen, J., and Ménard, C. (2010). Aligning modes of organization with technology: Critical transactions in the reform of infrastructures. Journal of Economic Behavior 83 Organization, 75(3):494-505.

Laffont, J.-J. and Martimort, D. (2009). The theory of incentives: the principal-agent model. Princeton University Press, Princeton.

Marshall, G. R. (2013). Transaction costs, collective action and adaptation in managing complex social-ecological systems. Ecological Economics, 88:185-194.

McCann, L. (2013). Transaction costs and environmental policy design. Ecological Economics, 88:253-262.

McCann, L., Colby, B., Easter, K. W., Kasterine, A., and Kuperan, K. V. (2005). Transaction cost measurement for evaluating environmental policies. Ecological Economics, 52(4):527-542.

Mettepenningen, E., Verspecht, A., and Van Huylenbroeck, G. (2009). Measuring private transaction costs of European agri-environmental schemes. Journal of Environmental Planning and Management, 52(5):649667.

Modell, S. (2009). Institutional Research on Performance Measurement and Management in the Public Sector Accounting Literature: A Review and Assessment. Financial Accountability 83 Management, 25(3):277303.

Moss, T. (2004). The governance of land use in river basins: prospects for overcoming problems of institutional interplay with the EU Water Framework Directive. Land Use Policy, 21(1):85-94.

Ménard, C. (2009). Redesigning Public Utilities: the key role of micro-institutions. In Corruption, Development and Institutional Design, pages 189-202. Palgrave Macmillan UK, London.

Ménard, C. (2011). A new institutional economics perspective on environmental issues. Environmental Innovation and Societal Transitions, 1(1):115-120.

Ménard, C. (2014). Embedding organizational arrangements: towards a general model. Journal of Institutional Economics, 10(4):567-589.

Ménard, C. and Peeroo, A. (2011). Liberalization and the Water Sector: Three Leading Models. In Handbook of Liberalization, pages 310-327. Routledge, Cheltenham. 
Ménard, C. and Saleth, M. (2013). The Effectiveness of Alternative Water Governance Arrangements. In Investing in Water for a Green Economy. Services, Infrastructure, Policies, and Management, pages 152-174. Routledge, London.

Nahrath, S. and Bréthaut, C. (2016). Coordination Between Institutional Resource Regimes as a Condition for Sustainable Management of Alpine Touristic Resources. Journal of Alpine Research / Revue de géographie alpine, (104-3).

North, D. C. (2005). Understanding the process of economic change. Princeton, princeton university press edition.

Ostrom, E. (1990). Governing the commons. The evolution of institutions for collective action. Cambridge University Press, Cambridge.

Ostrom, E. (2005). Understanding Institutional Diversity. Princeton University Press, stu - student edition edition.

Ostrom, E. (2009). A General Framework for Analyzing Sustainability of Social-Ecological Systems. Science, 325(5939):419-422.

Ostrom, E. (2011). Background on the Institutional Analysis and Development Framework. Policy Studies Journal, 39(1):7-27.

Pahl-Wostl, C., Holtz, G., Kastens, B., and Knieper, C. (2010). Analyzing complex water governance regimes: the Management and Transition Framework. Environmental Science 8$\}$ Policy, 13(7):571-581.

Phan, T.-H. D., Brouwer, R., and Davidson, M. D. (2017). A Global Survey and Review of the Determinants of Transaction Costs of Forestry Carbon Projects. Ecological Economics, 133:1-10.

Rendón Thompson, O., Paavola, J., Healey, J., Jones, J., Baker, T., and Torres, J. (2013). Reducing Emissions from Deforestation and Forest Degradation (REDD+): Transaction Costs of Six Peruvian Projects. Ecology and Society, 18(1).

Renou, Y. (2017). Performance indicators and the new governmentality of water utilities in France. International Review of Administrative Sciences, 83(2):378-396.

Roland, G. (2004). Understanding institutional change: Fast-moving and slow-moving institutions. Studies in Comparative International Development, 38(4):109-131.

Rothmayr, C. (2001). Towards the judicialisation of Swiss politics? West European Politics, 24:77-94.

Saleth, R. M. and Dinar, A. (2005). Water institutional reforms: theory and practice. Water Policy, 7(1):119.

Saleth, R. M. and Dinar, A. (2008). Linkages within institutional structure: an empirical analysis of water institutions. Journal of Institutional Economics, 4(3):375-401.

Schlager, E. and Ostrom, E. (1992). Property-Rights Regimes and Natural Resources: A Conceptual Analysis. Land Economics, 68(3):249. 
Schultz, L., Folke, C., Österblom, H., and Olsson, P. (2015). Adaptive governance, ecosystem management, and natural capital. Proceedings of the National Academy of Sciences, 112(24):7369-7374.

Scott, C. A., Pierce, S. A., Pasqualetti, M. J., Jones, A. L., Montz, B. E., and Hoover, J. H. (2011). Policy and institutional dimensions of the water-energy nexus. Energy Policy, 39(10):6622-6630.

Shleifer, A. and Vishny, R. W. (1994). Politicians and Firms. The Quarterly Journal of Economics, 109(4):995-1025.

Spiller, P. T. (2013). Transaction cost regulation. Journal of Economic Behavior E Organization, 89:232-242.

Swyngedouw, E. (2014). 'Not A Drop of Water...': State, Modernity and the Production of Nature in Spain, 1898-2010. Environment and History, 20(1):67-92.

Teisman, G. R. and Edelenbos, J. (2011). Towards a perspective of system synchronization in water governance: a synthesis of empirical lessons and complexity theories. International Review of Administrative Sciences, 77(1):101-118.

Tsanga-Tabi, M. and Verdon, D. (2014). New public service performance management tools and public water governance: the main lessons drawn from action research conducted in an urban environment. International Review of Administrative Sciences, 80(1):213-235.

van den Bergh, J. C. J. M., Truffer, B., and Kallis, G. (2011). Environmental innovation and societal transitions: Introduction and overview. Environmental Innovation and Societal Transitions, 1(1):1-23.

Varone, F. and Nahrath, S. (2014). Regulating the use of natural resources: When policy instruments meet property rights. In L'instrumentation de l'action publique. Controverses, resistances, effets, pages 237-264. Presses de Sciences Po, Paris.

Varone, F., Reynard, E., Kissling-Näf, I., and Mauch, C. (2002). Institutional Resource Regimes: The Case of Water Management in Switzerland. Integrated Assessment, 3(1):78-94.

Vatn, A. (2005). Institutions and the Environment. Edward Elgar Publishing, Cheltenham.

Williamson, O. E. (2000). The New Institutional Economics: Taking Stock, Looking Ahead. Journal of Economic Literature, 38(3):595-613.

Williamson, O. E. (2005). The Economics of Governance. The American Economic Review, 95(2):1-18.

Young, O. R. (2010). Institutional dynamics: Resilience, vulnerability and adaptation in environmental and resource regimes. Global Environmental Change, 20(3):378-385. 